\title{
Approach to Cushing's syndrome in pregnancy: two cases of Cushing's syndrome in pregnancy and a review of the literature
}

\author{
Wei Lin ${ }^{1}$, Hui-Bin Huang ${ }^{1}$, Jun-Ping Wen ${ }^{1}$, Neng-Ying Wang ${ }^{1}$, Shuang-Yu Wang ${ }^{2}$, Chen Wang ${ }^{3}$, \\ Gang Chen ${ }^{1}$
}

${ }^{1}$ Department of Endocrinology, ${ }^{2}$ Department of Imaging, ${ }^{3}$ Department of Pathology, Shengli Clinical Medical College of Fujian Medical University, Fujian Provincial Hospital, Fuzhou 350001, China

Contributions: (I) Conception and design: G Chen, W Lin; (II) Administrative support: G Chen, JP Wen; (III) Provision of study materials or patients: W Lin, JP Wen; (IV) Collection and assembly of data: W Lin, NY Wang, SY Wang, C Wang; (V) Data analysis and interpretation: W Lin, HB Huang; (VI) Manuscript writing: All authors; (VII) Final approval of manuscript: All authors.

Correspondence to: Gang Chen. Department of Endocrinology, Shengli Clinical Medical College of Fujian Medical University, Fujian Provincial Hospital, Fuzhou 350001, China. Email: chengangfj@163.com.

\begin{abstract}
Cushing's syndrome (CS) rarely occurs during pregnancy. The primary aim of this article is to propose a therapeutic approach to CS in pregnancy. Here, we present two cases of CS in pregnancy and a literature review. This article proposes the early diagnostic points, especially the clinical approach to this medical condition, mainly for pregnant women without a previous diagnosis of CS. More importantly, we present therapeutic strategies for CS during pregnancy, especially glucocorticoid replacement for perioperative, postoperative, and perinatal periods in pregnant women with CS in order to minimize complications for both mother and fetus. At the same time, we also assess the anxiety status of patients. This article summarizes the approach to CS in pregnancy, not only with a physiological assessment but with a psychological assessment as well.
\end{abstract}

Keywords: Cushing's syndrome (CS); pregnancy; diagnosis; anxiety; glucocorticoids replacement

Submitted May 08, 2019. Accepted for publication Jul 24, 2019.

doi: $10.21037 /$ atm.2019.07.94

View this article at: http://dx.doi.org/10.21037/atm.2019.07.94

\section{Introduction}

Cushing's syndrome (CS) is also known as hypercortisolism, and can interfere with the development of normal follicles, inhibit ovulation, and lead to infertility $(1,2)$. Hunt and McConahy first reported cases of CS found during pregnancy in 1953 (3). Therefore, there are very few reported cases of pregnancy with CS. To date, several studies $(2,4-7)$ have shown untreated CS to be associated with major maternal complications and adverse fetal outcomes, including diabetes, hypertension, heart failure, and preeclampsia, along with premature delivery, spontaneous abortion, stillbirth, perinatal death, and intrauterine growth retardation; given these complications, we need our clinicians, especially endocrinologists, obstetricians and, gynecologists, to be vigilant. Furthermore, because the clinical features of pregnancy with CS and pregnancy without CS greatly overlap, the challenge and difficulty of diagnosis are significant. In recent years, most of the literature on pregnancy with CS has only reported the principles of diagnosis and treatment of the disease; there have been few detailed early diagnostic ideas and assessment of psychological states and management strategies for pregnancy combined with CS, especially in the literature on perioperative, postoperative, and perinatal glucocorticoid replacement programs. Therefore, this article summarizes the diagnosis and treatment of two patients with pregnancy complicated with CS who were recently admitted to our hospital. It also provides a literature review and proposes a clinical response to pregnancy and CS and to the glucocorticoid replacement program in different stages of perioperative, postoperative, and perinatal periods. Moreover, we provide some suggestions for screening 
Table 1 General and biochemical examination of abnormal items

\begin{tabular}{|c|c|c|c|c|c|c|c|c|}
\hline Items & WBC $\left(10^{9} / \mathrm{L}\right)$ & $\mathrm{Ne}(\%)$ & ALB (g/L) & $\begin{array}{c}\mathrm{TG} \\
(\mathrm{mmol} / \mathrm{L})\end{array}$ & $\begin{array}{c}\mathrm{CHOL} \\
(\mathrm{mmol} / \mathrm{L})\end{array}$ & $\begin{array}{c}\mathrm{HDL} \\
(\mathrm{mmol} / \mathrm{L})\end{array}$ & $\begin{array}{c}\mathrm{LDL} \\
(\mathrm{mmol} / \mathrm{L})\end{array}$ & $\begin{array}{c}\mathrm{K}^{+} \\
(\mathrm{mmol} / \mathrm{L})\end{array}$ \\
\hline Reference & $3.5-9.5$ & $40.0-75.0$ & $40-55$ & $<1.7$ & $<5.2$ & $1.00-1.70$ & $1.30-3.60$ & $3.5-5.3$ \\
\hline Case 1 & 12.7 & 80.9 & 33 & 2.35 & 6.03 & 1.71 & 3.96 & 3.2 \\
\hline Case 2 & 7.2 & 82.2 & 40 & 1.23 & 6.32 & 3.19 & 3.37 & 3.2 \\
\hline
\end{tabular}

WBC, leukocyte; NE, neutrophil ratio; ALB, serum albumin; TG, triglyceride; CHOL, total cholesterol; HDL, high-density lipoprotein; LDL, low-density lipoprotein; $\mathrm{K}^{+}$, serum potassium.

pregnant women who may have CS and recommend doctors pay attention to the psychological states of the patients.

\section{Methods}

We present two cases of CS in pregnancy and a literature review and propose the approach to the CS in pregnancy.

\section{Case 1}

\section{Medical history}

A 32-year-old female patient complained of " $20^{+6}$ weeks of amenorrhea and high blood pressure for 1 month". Twenty ${ }^{+6}$ weeks before admission, due to infertility, the patient had an in vitro test tube embryo transfer and was successfully impregnated. One month prior to admission, at $16^{+2}$ weeks of pregnancy, the patient's blood pressure was as high as $183 / 99 \mathrm{mmHg}$. In the same month, the skin of the outer thigh and lower abdomen was found to have purple streaks, and the patient experienced increased facial and back pain, accompanied by swelling of the lower extremities, as well as fatigue and weakness. She considered the symptoms to be "discomfort during pregnancy" and did not see a doctor. Two weeks before admission to our hospital $\left(18^{+2}\right.$ weeks of pregnancy) she had double lower extremity edema, a blood pressure of 156/92 $\mathrm{mmHg}$, and her blood electrolytes were "potassium $3.01 \mathrm{mmol} / \mathrm{L}$ ". Due to this and repeated recommendations of her local hospital, she was admitted to our hospital. During pregnancy, her weight increased by $7 \mathrm{~kg}$. She denied any history of previous glucocorticoid use. Her menstrual history was as follows: years since menarche, 12; cycle, 5-6/28-35 days; last menstruation, May 23, 2017. Her personal history and family history were not remarkable.

\section{Upon physical examination}

The patient had a body temperature of $36.5^{\circ} \mathrm{C}$, a pulse of 98 beats/min, a respiration rate of 19 beats/min, a blood pressure of $159 / 113 \mathrm{mmHg}$, a height of $158 \mathrm{~cm}$, a weight of $63 \mathrm{~kg}$, a waist circumference of $102.0 \mathrm{~cm}$, and a body mass index (BMI) of $25.24 \mathrm{~kg} / \mathrm{m}^{2}$. She had a full-moon face and a buffalo hump. Her skin was thin, her limbs (the armpits and the outer thighs) and her lower abdomen were covered with scattered purple lines, and her forehead and the back of her neck were thickened with visible acne and thickening of the fat on both sides of the neck. There were no abnormalities found in the heart, lung, or in any abdominal examination. The patient had two toes with gray toenails and mild depression of both lower limbs. The patient scored 9 points on the Hamilton anxiety scale ( $>29$ points severe anxiety; $>21$ points obvious anxiety; $>14$ points must have anxiety; $>7$ points may have anxiety; $\leq 7$ points no anxiety symptoms), 7 points on the Hamilton depression scale ( $>30$ points major depression; $>20$ points moderate depression; $>17$ points mild depression), and 7 points on the Ferriman and Gallwey hirsutism scale.

\section{Laboratory inspection}

(I) Routine laboratory inspection (Table 1); (II) an oral glucose tolerance test (Table 2); (III) thyroid hormone tests (Table 3); (IV) endocrine hormone tests (Table 4) were conducted; (V) adrenocorticotropic hormone (ACTH), cortisol (COR), and 24-hour urinary free cortisol (UFC) were determined (Table 5).

\section{Imaging examination findings}

Full abdomen color ultrasound revealed a single intrauterine pregnancy with a viable embryo with no obvious abnormalities. Adrenal gland magnetic resonance scan (Figure 1): (I) the left adrenal gland had lateral fat lesions and an adenoma (size approximately $2.8 \mathrm{~cm} \times 3.5 \mathrm{~cm}$ ); (II) a liver scan revealed a very heterogeneous fatty liver.

\section{Case 2}

\section{Medical history}

The 23 -year-old patient was observed with " $16^{+4}$ weeks 
Table 2 Oral glucose tolerance test

\begin{tabular}{|c|c|c|c|c|c|}
\hline Items & Fasting & $30 \mathrm{~min}$ & $60 \mathrm{~min}$ & $120 \mathrm{~min}$ & $180 \mathrm{~min}$ \\
\hline Blood sugar (mmol/L) & 5.52 & 12.13 & 13.29 & 15.00 & 10.11 \\
\hline Insulin (mU/L) & 29.56 & 144.30 & 135.90 & 335.70 & 327.10 \\
\hline C peptide ( $\mu \mathrm{g} / \mathrm{L})$ & 6.21 & 13.38 & 16.5 & 26.65 & 28.27 \\
\hline Blood sugar (mmol/L) & 4.66 & 11.92 & 12.76 & 8.72 & 3.41 \\
\hline Insulin (mU/L) & 9.75 & 133.1 & 158.90 & 172.30 & 15.68 \\
\hline C peptide ( $\mu \mathrm{g} / \mathrm{L})$ & 2.72 & 15.33 & 19.04 & 22.53 & 7.36 \\
\hline
\end{tabular}

Table 3 Thyroid function

\begin{tabular}{lcccccc}
\hline Items & $\mathrm{sTSH}(\mathrm{mlU} / \mathrm{L})$ & $\mathrm{FT}_{3}(\mathrm{pmol} / \mathrm{L})$ & $\mathrm{FT}_{4}(\mathrm{pmol} / \mathrm{L})$ & $\mathrm{rT3}(\mathrm{nmol} / \mathrm{L})$ & $\mathrm{TPOAb}(\mathrm{IU} / \mathrm{mL})$ & $\mathrm{TGAb}(\mathrm{IU} / \mathrm{mL})$ \\
\hline Reference & $0.27-4.20$ & $3.10-6.80$ & $12.00-22.00$ & $0.31-1.01$ & $0.00-34.00$ & $0.10-115.00$ \\
Case 1 & 0.39 & 2.86 & 8.98 & 0.58 & 15.24 & 16.56 \\
Case 2 & 0.01 & 2.96 & 13.10 & - & 16.37 & 11.20 \\
\hline
\end{tabular}

sTSH, hypersensitive thyroid stimulating hormone; $\mathrm{FT}_{3}$, free triiodothyronine; $\mathrm{FT}_{4}$, free thyroxine; $\mathrm{rT3}$, anti-triiodothyronine; $\mathrm{TPOAb}$, thyroid peroxidase antibody; TGAb, thyroglobulin antibody.

Table 4 Sex hormones, growth hormone, dehydroepiandrosterone and its sulfates with methoxy norepinephrine and methoxy adrenaline

\begin{tabular}{|c|c|c|c|c|c|c|c|c|c|}
\hline Items & LH (IU/L) & FSH (IU/L) & $\mathrm{E}_{2}(\mathrm{pg} / \mathrm{mL})$ & $\mathrm{T}(\mathrm{nmol} / \mathrm{L})$ & PRL (ng/mL) & $\mathrm{GH}(\mathrm{ng} / \mathrm{mL})$ & DHEAs $(\mu \mathrm{g} / \mathrm{dL})$ & NMN (nmol/L) & $\mathrm{MN}(\mathrm{nmol} / \mathrm{L})$ \\
\hline Case 1 & 0.43 & 0.19 & 4073 & 1.90 & 21.80 & 1.04 & 91.20 & 0.60 & $<0.08$ \\
\hline Case 2 & 1.08 & 0.22 & 3850 & 3.74 & 29.67 & 1.29 & 57.80 & 0.18 & $<0.08$ \\
\hline
\end{tabular}

$\mathrm{LH}$, luteinizing hormone; FSH, follicle stimulating hormone; E2, estradiol; T, testosterone; PRL, prolactin; DHEAs, dehydroepiandrosterone and its sulfate; NMN, methoxy norepinephrine; MN, methoxy adrenergic.

Table 5 Cortisol-related indicators

\begin{tabular}{|c|c|c|c|c|c|}
\hline Reference & $240.00-680.00$ & $<276$ & - & $7.20-63.60$ & 58-395 \\
\hline First & 684.00 & 650.13 & 694.44 & 1.07 & $1,517.63$ \\
\hline Second & - & - & - & $<1.00$ & $2,200.00$ \\
\hline First & 877.00 & 774.24 & 745.58 & 1.40 & $1,750.00$ \\
\hline Second & 882.14 & 800.00 & 777.66 & 1.15 & $1,734.00$ \\
\hline
\end{tabular}

COR, cortisol; ACTH, adrenocorticotropic hormone; 24-h-UFC, 24-hour urinary free cortis. 

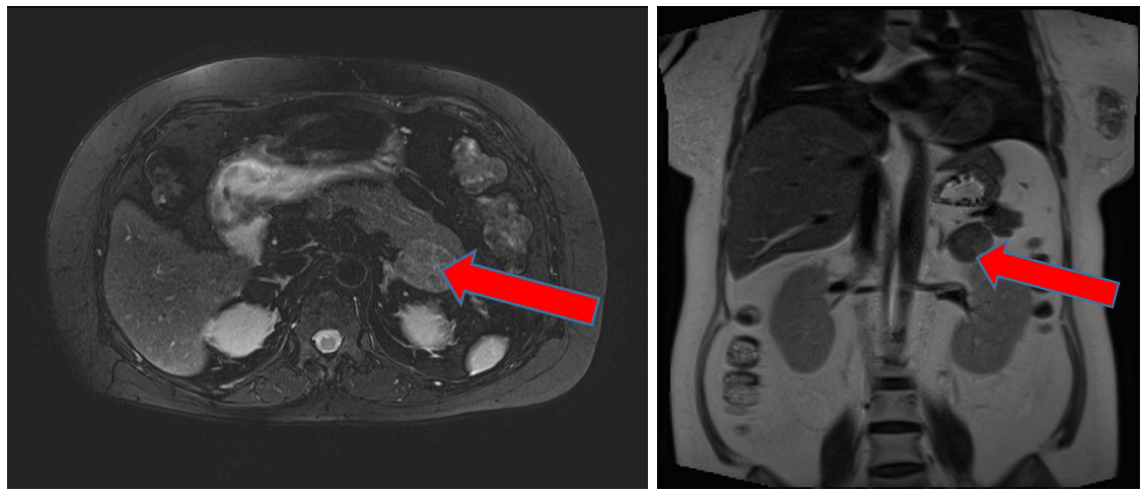

Figure 1 Case 1 adrenal gland MRI. It shows a left adrenal mass $(2.8 \mathrm{~cm} \times 3.5 \mathrm{~cm})$. MRI, magnetic resonance imaging.
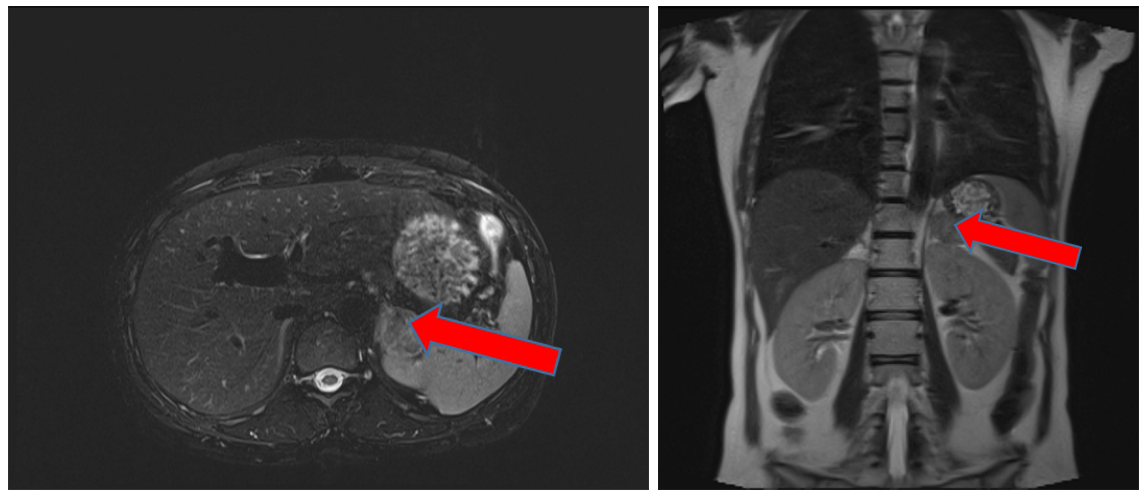

Figure 2 Case 2 adrenal gland MRI. It shows a left adrenal mass $(3.0 \mathrm{~cm} \times 3.5 \mathrm{~cm})$. MRI, magnetic resonance imaging.

of amenorrhea, progressive increase in body weight for 12 weeks, and edema for 1 month". Pregnancy was found $16^{+4}$ weeks before admission. During the first semester of pregnancy, she had progressive weight gain, a rounded and reddened face, increased hemorrhoids, and increased facial, torso hair, and neck hair. She often felt fatigued and weakness. After her initial admission, she was treated in our hospital. Since becoming pregnant, her weight increased by $10 \mathrm{~kg}$. She denied a history of previous glucocorticoid use. Her menstrual history included the following: years since menarche, 12; cycle, 5/28 days; last menstrual period, October 14, 2017. Her personal history and family history were not remarkable.

\section{Upon physical examination}

The patient's body temperature was $36.5^{\circ} \mathrm{C}$, her pulse was 88 beats/min, her respiration was 20 beats/min, her blood pressure was $140 / 70 \mathrm{mmHg}$, her height was $163 \mathrm{~cm}$, her weight was $55 \mathrm{~kg}$, her waist circumference was $85.0 \mathrm{~cm}$, and her BMI was $20.7 \mathrm{~kg} / \mathrm{m}^{2}$. She had a full-moon face with a more reddened appearance, a buffalo hump, thin skin, and no purple lines anywhere on the body skin. Compared with pre-pregnancy, the hair on the forehead and back of the neck had increased, and multiple areas of acne were visible. The fat on both sides of her neck was thickened. There were no abnormalities in the heart, lung, or in any abdominal examination. The patient had gray toenails on two toes. Upon psychological examination, the patient scored 15 points on the Hamilton anxiety scale, 7 points on the Hamilton depression scale, and 6 points on the Ferriman and Gallwey hirsutism scale.

\section{Laboratory inspection}

The same as discussed above (see Tables 1-5).

\section{Imaging examination findings}

Total abdominal color ultrasound revealed that the left adrenal was hypoechoic $(3.1 \mathrm{~cm} \times 3.0 \mathrm{~cm})$, which indicated a possible adenoma. The adrenal gland magnetic resonance 
scan (Figure 2) revealed that (I) the left adrenal area occupying lesions may have been adenomas (size approximately $3.5 \mathrm{~cm}$ $\times 3.0 \mathrm{~cm}$ ) and revealed (II) intrauterine pregnancy.

\section{Approach to Cushing's syndrome in pregnancy}

\section{Background knowledge and epidemiological characteristics}

A series of physiological changes occur in the parental hypothalamic-pituitary-adrenal (HPA) axis during normal pregnancy (8). (I) The placenta produces ACTH. The placental-derived ACTH causes elevated maternal blood ACTH levels but is still pulsed. (II) As the blood ACTH increases and the maternal sensitivity to ACTH increases, the total plasma, and free COR concentrations in the mother increase. (III) The placenta produces corticotropinreleasing hormone (CRH). (IV) Increased production of estrogen-induced cortisol-binding globulin (CBG) during pregnancy and elevated progesterone may have an effect on antagonizing glucocorticoids. (V) During the pregnancy, the setting point of the negative feedback mechanism regulating ATCH secretion in the HPA axis changes. Based on the physiological changes during pregnancy, the concentration of serum and salivary COR in pregnant women increases, and the concentration of UFC increases 2-3 times in middle and late pregnancy, but the circadian rhythm of serum COR in normal pregnant women can still be maintained.

\section{Clinical features of pregnancy with CS}

The clinical features of CS during pregnancy may overlap with many non-CS normal pregnant women in terms of many symptoms and signs (e.g., weight gain, fatigue, edema, hypertension, hyperglycemia, etc.). Therefore, CS with pregnancy is often not discovered until mid-pregnancy $(2,9)$. This is because doctors and patients often attribute changes in appearance to pregnancy rather than CS $(2,6)$. Furthermore, some of the symptoms of CS may also be attributed to pregnancy complications (e.g., gestational diabetes, aura eclampsia, etc.). Thus, leading to a delay in the diagnosis of CS with pregnancy $(1,4,9)$. The incidence of ACTHindependent CS is increased in pregnant women compared with nonpregnant CS populations. One study included approximately 140 cases of reported pregnancy combined with CS, with $60 \%$ being ACTH-independent CS (48\% adenoma, $10 \%$ cancer) $(2,6,9,10)$. In nonpregnant women with CS, the incidence of adrenal adenomas is only approximately $15 \%$ (2). It has been reported in the literature (11-13) that the mechanism of elevated adrenal adenoma in pregnancy with CS may be due to a variety of hormone receptors, especially ectopic expression of luteinizing hormone ( $\mathrm{LH}$ )/chorionic gonadotropin receptor in the adrenal cortex and estrogendependent nodular adrenal hyperplasia.

\section{The pregnancy diagnosis of CS}

\section{Qualitative diagnosis}

First, it is necessary to exclude the history of use of exogenous glucocorticoids. Second, the diagnosis should be based on the pathophysiological characteristics of HPA axis changes during pregnancy, combined with clinical features and 24-hour UFC.

We recommend that clinicians be alert to the following signs indicating the possibility of CS before and/or during pregnancy: (I) physical symptoms such as full moon face, thin skin, and large purple striae; (II) no history of hypertension and diabetes before pregnancy, but symptoms such as hypertension and hyperglycemia appearing before 20 weeks of gestation; (III) significant increases in hair and acne, especially hair and acne that develops rapidly or prematurely (before 12 weeks of gestation); (IV) hypokalemia; (V) premature excessive weight gain in early pregnancy and/or at the beginning of the second trimester, especially if inconsistent with the number of weeks of pregnancy.

For patients with infertility or irregular menstruation before pregnancy, when the $1-5$ symptoms and signs above occur during pregnancy, it is necessary for the endocrinologist to attribute greater importance to these symptoms when considering a diagnosis.

When UFC exceeds 3 times the nonpregnant upper limit of normal ( $\geq 2$ UFC) and the blood circadian rhythm disappears, the patient should be considered to have CS in pregnancy. In addition, due to changes in the HPA axis during pregnancy, the inhibition rate of the low-dose dexamethasone suppression test commonly used in the diagnosis of CS in nonpregnant populations is reduced, and the risk of false-positive results is greatly increased (14). Therefore, we do not recommend this check for pregnant patients with suspected CS.

\section{Positioning diagnosis}

Once the diagnosis of CS is clear, it is feasible to measure blood ACTH ( $\geq 2$ times, confirmed in the other day). When blood ACTH is repeatedly measured $<10 \mathrm{pg} / \mathrm{mL}(<2.2 \mathrm{pmol} / \mathrm{L})(15)$, suggesting non- 
ACTH-dependent CS, then an adrenal ultrasound can be performed. If the adrenal ultrasound results are negative, adrenal gland MRI can be performed. When blood ACTH is $>20 \mathrm{pg} / \mathrm{mL}(>4.4 \mathrm{pmol} / \mathrm{L})(15)$, it suggests ACTH-dependent CS, and it is acceptable to perform pituitary MRI. Because of the potential adverse effects of fetal MRI in early pregnancy, pituitary MRI can be performed in the middle and late stages of pregnancy, but sputum contrast agents cannot be used during pregnancy. However, since the CRH secreted by the placenta is not inhibited by hypercortisolemia, the blood ACTH may not be inhibited in pregnant CS patients with adrenal diseases. Therefore, when blood ACTH is between 10 and $20 \mathrm{pg} / \mathrm{mL}$ (2.2 to $4.4 \mathrm{pmol} / \mathrm{L}$ ), further examination may be essential. Only if a pheochromocytoma can be excluded, the high-dose $(8 \mathrm{mg})$ dexamethasone inhibition test can be considered to identify CS and Cushing's disease (CD). In general, high-dose dexamethasone has no inhibitory effect on non-ACTH-dependent CS patients, but it inhibits serum COR in patients with CD $(2,16,17)$. However, as a consequence of the physiological changes of the HPA axis during pregnancy, blood COR cannot be completely inhibited in some patients with CD (2), so this test may not be able to identify all patients with CS. It has been reported in the literature that the CRH stimulation test and inferior petrosal sinus sampling (IPSS) have been performed in a small number of pregnant patients (2). Although the above two tests may be helpful in the diagnosis of women with suspected CD with high ACTH levels, there is currently insufficient evidence to show that the above tests are safe and reliable in pregnant people.

\section{Treatment strategies for pregnancy with CS}

Pregnancy with CS is a high-risk pregnancy group, and these high-risk pregnant women and fetuses should be monitored and followed up by a multidisciplinary medical team comprising clinicians from obstetrics and gynecology, endocrinology, anesthesiology, and urology. Current research reports that active treatment of CS during pregnancy can significantly reduce the incidence of premature birth and abortion, increasing live birth rates $(2,18,19)$. However, there are also reports in the literature suggesting that even successful surgery may not delay or change the adverse pregnancy outcomes of eclampsia and preterm birth $(20,21)$. These exceptions may be due to the diagnostic confusion of pregnancy with CS, which usually results in treatment in the third trimester of pregnancy. On the other hand, it may be due to excessive glucocorticoid replacement during perioperative, postoperative, and perinatal periods. Therefore, this paper elaborates upon the glucocorticoid replacement strategies in different stages of a perioperative, postoperative, and perinatal period of pregnancy in women with CS.

\section{Surgical treatment}

The relevant surgical methods mainly include unilateral or bilateral adrenalectomy and transsphenoidal (TSS) pituitary adenoma resection. Adrenal tumor resection in patients with adrenal tumors is beneficial $(19,22,23)$, and the progeny live birth rate of patients with pregnancy after surgery is approximately $87 \%(2,9,19,24)$. The main surgical methods are open surgery and laparoscopic adrenalectomy (25). In nonpregnant patients suspected of having adrenal adenomas, laparoscopic methods have become the primary treatment option (26). In fact, even in late pregnancy, various laparoscopic procedures have been widely and safely applied during pregnancy (27), and laparoscopic surgery has proven to be safe (27). Therefore, for most patients with CS (an adrenal tumor), we recommend laparoscopic adrenalectomy at the beginning of the second trimester (16-21 weeks) (25). In addition, in a retrospective study of 40 patients with $\mathrm{CD}$, approximately $20 \%$ underwent TSS surgery (28), while the remaining patients received medication and/or adrenalectomy; one of the patients with unexplained CS during pregnancy was treated with pituitary radiation $(2,9)$.

\section{Medical treatment}

The literature reports that $(10,29)$ metyrapone is suitable for primary drug therapy in patients with pregnancy and CS who are unable to undergo surgery or who are ready to give birth and in whom metyrapone is well-tolerated. However, the drug may cause hypertension to worsen and progress into pre-eclampsia, which limits the drug's use $(30,31)$. In addition, metyrapone can be excreted in breast milk, so it should be used carefully during breastfeeding $(30,31)$. In addition to metyrapone, ketoconazole was successfully used in three patients with pregnancy and CS (32-34), but the drug is FDA category $\mathrm{C}$, so it is only used for patients who require urgent medical treatment but cannot tolerate metyrapone. Another drug, estradiol, is infused intravenously and is often used for anesthesia induction. The subhypnotic dose of the drug can rapidly reduce steroid production within 12-24 hours, and it is the only treatment for critically ill patients with severe hypercortisolism who 
are not undergoing immediate surgery and cannot take oral medications (35). This drug is also useful for CS with acute refractory symptoms such as respiratory failure or severe mental illness. Further, it can be an effective bridge for other drugs or surgical treatments (35). Unfortunately, there is currently no literature reporting on the use of estradiol in patients with pregnancy and CS.

\section{Perioperative management of pregnancy with CS}

\section{Initial postoperative remission (35)}

There are currently no specific data for the pregnant population, and our knowledge is mainly based on data on postoperative remission in nonpregnant populations. Serum, blood pressure, and blood glucose levels should be monitored during and after surgery. Seven days after TSS selective tumor resection, blood COR (before administration) should be $<138 \mathrm{nmol} / \mathrm{L}(5 \mu \mathrm{g} / \mathrm{dL})$ or urine UFC should be $<28-56 \mathrm{nmol} / \mathrm{L}(10-20 \mu \mathrm{g} / \mathrm{dL})$; when unilateral adrenalectomy has been performed, if blood COR is $<50 \mathrm{nmol} / \mathrm{L}(1.8 \mu \mathrm{g} / \mathrm{dL})$ in the morning, then CS can be considered alleviated. Postoperative care should be taken to assess symptoms of glucocorticoid withdrawal in patients, including anorexia, nausea, weight loss, and other nonspecific manifestations, such as fatigue, myalgia, joint pain, and skin desquamation. The recovery from symptoms can take approximately 1 year or longer. The recovery time of the HPA axis ranges from 6 to 12 months after ACTHdependent CS and 18 months after unilateral adrenalectomy.

\section{Replacement of glucocorticoids after surgery}

The goal of glucocorticoid therapy after surgery is to achieve a physiological dose of glucocorticoid replacement to improve the prognosis of the mother and the fetus. In the second trimester and the third trimester, careful monitoring and titration are needed to avoid excessive corticosteroid replacement. Hydrocortisone is the first choice for chronic replacement therapy during pregnancy (36-38).

On the day of surgery, glucocorticoids [50 to $100 \mathrm{mg}$ hydrocortisone, intravenous (IV) injection] can be used every 8 hours during and after surgery. In the next 2 days (first and the second day after surgery), the dose of hydrocortisone is gradually reduced to $50 \mathrm{mg}$ every 8 hours, after which the IV dose can be reduced to $25 \mathrm{mg}$ every 8 hours (36-38). This dose has provided coverage of glucocorticoids and mineralocorticoids. On the third postoperative day, most patients are able to take oral replacement doses of hydrocortisone. There is currently no consensus on whether a superphysiological replacement dose (twice the normal dose) should be given for several weeks to alleviate withdrawal symptoms (weakness, anorexia, muscle, and joint pain) (36-38).

The daily physiological production of COR is approximately $5-6 \mathrm{mg} / \mathrm{m}^{2}$ per body surface area (39). Postoperative oral glucocorticoid replacement therapy is given as hydrocortisone $(38,40) 12-15 \mathrm{mg} / \mathrm{m}^{2}$ per body surface area or as a dose of $15-25 \mathrm{mg}$, usually 2 to 3 times a day, with $50-66 \%$ of the daily dose given in the morning when awakening. If given twice a day, the second dose is usually given $6-8$ hours after the morning dosing (e.g., 6 a.m. for $2 / 3$ total replacement in the morning, 2 p.m. for $1 / 3$ full-day replacement in the afternoon). If it is administered 3 times a day $(38,40)$, the second dose is given 4-6 hours after the morning dose, and the third dose is given 4-6 hours later. Until the patient's early morning endogenous COR levels and the response to exogenous ACTH return to normal, patients should wear a medical wristband or carry a warning card before the HPA shaft is restored, and they should be instructed to increase the dose of hydrocortisone during stress until the pituitary-adrenal axis is fully restored $(38,40)$. We tend to avoid using superphysiological dose replacement therapy because it may extend the duration of the symptoms of CS. However, taking into account the specific physiological changes in pregnancy, the dose of hydrocortisone in the third trimester can be increased by approximately $20-40 \%$ (40).

\section{Review of the diagnosis and treatment of the two presented cases}

\section{Diagnosis}

In the first two cases, the clinical diagnosis was possible due to premature (before 20 weeks of gestation) hypertension, excessive hair growth, hypokalemia, and excessive weight gain in early and mid-pregnancy. After repeated measurements, the 24-hour UFC increased more than 4 times the upper limit of normal, which, combined with the disappearance of COR circadian rhythm, led to the diagnosis of suspected pregnancy with hypercortisolism. Further investigation determined that blood ACTH levels were less than $10 \mathrm{pg} / \mathrm{mL}$ on average, which, combined with the adrenal magnetic resonance imaging (MRI) results, established the clinical diagnosis of pregnancy with nonACTH-dependent hypercortisolism. 

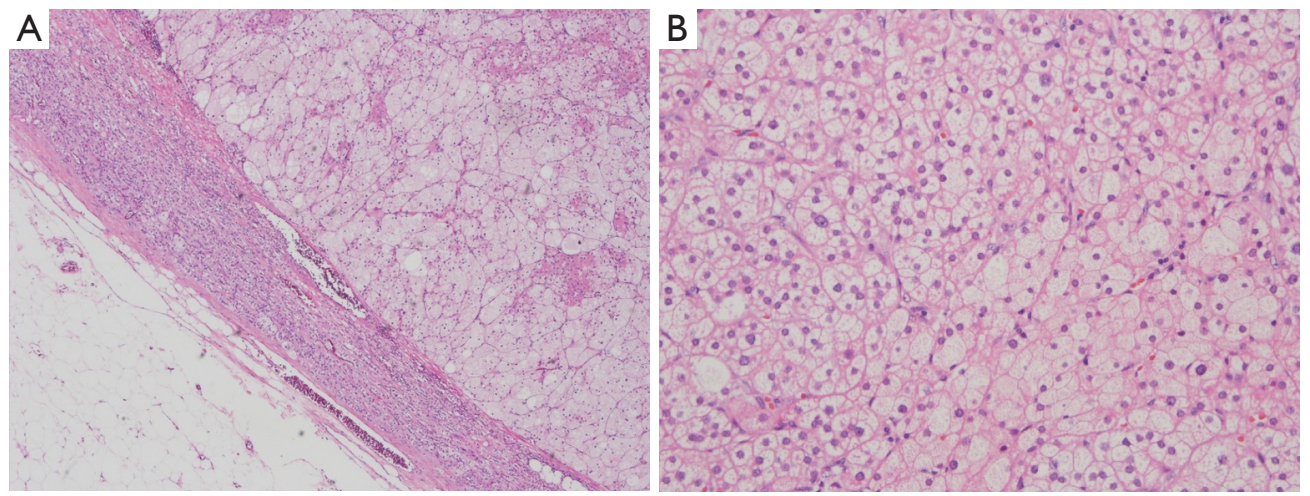

Figure 3 Case 1 histology results. (A) Subcapsular $\times 4$ times; (B) subcapsular $\times 20$ times.
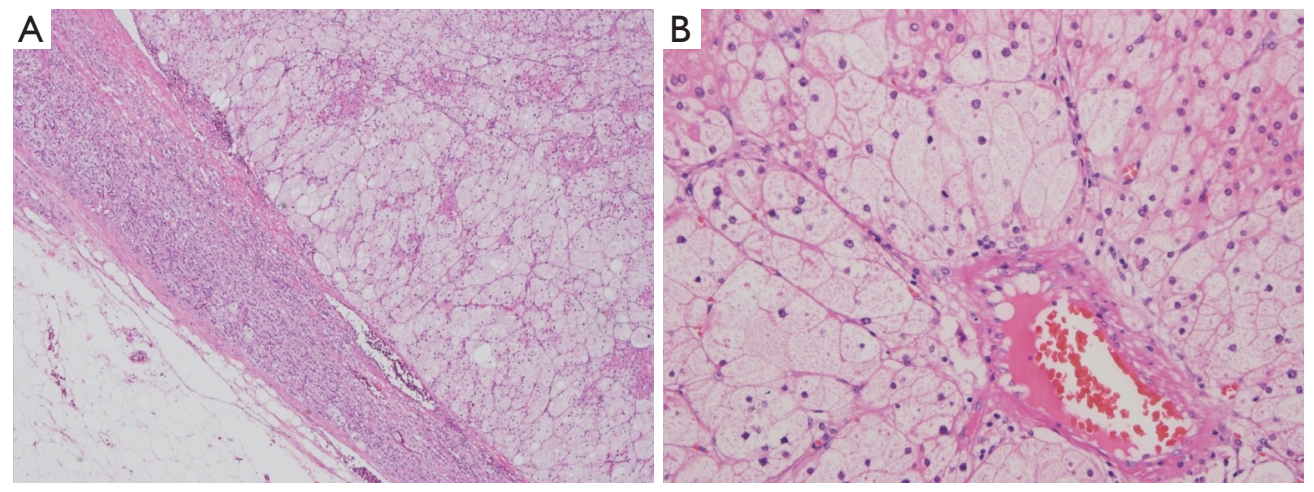

Figure 4 Case 2 histology results. (A) Subcapsular $\times 4$ times; (B) subcapsular $\times 20$ times.

\section{Perioperative management}

After the diagnosis was clear, and after consultations in the related departments of obstetrics, anesthesiology, and urology were completed, the two patients were treated by experienced urologists in our hospital at $23^{+3}$ weeks of pregnancy (case 1) and $20^{+5}$ weeks of pregnancy (case 2) with "laparoscopic left adrenal adenoma resection". Case 1 patient's postoperative pathological findings (Figure 3) were (left adrenal gland) adrenal adenoma, cell growth, and incomplete capsule; case 2 patient's postoperative pathological finding (Figure 4) was (left adrenal gland) adrenal adenoma. The entire perioperative and postoperative glucocorticoid replacement regimen followed the protocol described above.

\section{Follow-up}

The case 1 patient was further adjusted to hydrocortisone $40 \mathrm{mg}$ at 6 a.m. and $20 \mathrm{mg}$ at 2 p.m. taken orally, according to her symptoms, blood pressure, blood sodium, and blood sugar status after 5 days of surgery. After that, the patient was discharged to the local hospital for further treatment. Because there was no oral hydrocortisone preparation, the patient was changed to methylprednisolone $4 \mathrm{mg}$ at $6 \mathrm{a} . \mathrm{m}$. and $2 \mathrm{mg}$ at $2 \mathrm{p} . \mathrm{m}$. taken orally. At $32^{+3}$ weeks of gestation, because of the pre-eclampsia, conservative treatment of obstetrics was not effective; the patient underwent cesarean section and delivered a premature baby boy with an Apgar score of 10 points after birth. The case 2 patient experienced repeated fatigue and anorexia after surgery, so hydrocortisone $40 \mathrm{mg}$ bid (administered at $6 \mathrm{a} . \mathrm{m}$. and 2 p.m.) was used as a COR replacement for 3 weeks (up to 4 weeks after surgery). Then, the patient began to suffer from insomnia in the third week after surgery. Considering the excessive dose of hormone replacement, the hydrocortisone was gradually reduced to $20 \mathrm{mg}$ (6 a.m. immediately after waking and $10 \mathrm{mg}$ at $2 \mathrm{p} . \mathrm{m}$.), taken orally, to relieve her symptoms. At $35^{+6}$ weeks of gestation, she delivered a baby boy with an Apgar score of 10 points after birth. 
In general, the increased incidence of anxiety and/or depression in pregnant women, combined with the effects of high glucocorticoids, makes the incidence of anxiety and depression in patients with pregnancy and CS higher. Pregnant women's anxiety, depression, and other adverse emotional conditions are very harmful to pregnant women and fetuses. In this paper, the two patients had different levels of anxiety and/or depression as determined by the Hamilton anxiety and depression scores. Therefore, we recommend that comprehensive psychological intervention and counseling be performed during perioperative, postoperative, and perinatal periods in patients with pregnancy with CS.

\section{Summary}

Whether it is recognized early during pregnancy or later, pregnancy with CS can interfere with early pregnancy and affect maternal and fetal outcomes. Perioperative, postoperative, and perinatal glucocorticoid replacement in patients undergoing surgery also affects pregnancy outcomes. Therefore, as clinicians, especially for obstetricians and gynecologists along with endocrinologists in primary hospitals, we need to raise awareness of this rare disease and strive for early detection and diagnosis and for timely and reasonable intervention, and we need to pay attention to the comprehensive management of the physiological and psychological aspects of perioperative, postoperative, and perinatal periods. However, there is currently limited experience in the diagnosis and treatment of pregnancy with CS, and further follow-up of patients and their offspring are needed.

\section{Acknowledgments}

None.

\section{Footnote}

Conflicts of Interest: The authors have no conflicts of interest to declare.

Ethical Statement: The authors are accountable for all aspects of the work in ensuring that questions related to the accuracy or integrity of any part of the work are appropriately investigated and resolved. This study obtained ethics approval from the Ethics Committee of Fujian Provincial Hospital. The number/ID of the approval is (K2007-08-003), and the participants gave informed consent before taking part.

\section{References}

1. Sheeler LR. Cushing's syndrome and pregnancy. Endocrinol Metab Clin North Am 1994;23:619-27.

2. Lindsay JR, Nieman LK. The hypothalamic-pituitaryadrenal axis in pregnancy: challenges in disease detection and treatment. Endocr Rev 2005;26:775-99.

3. Hunt AB, McConahey WM. Pregnancy associated with diseases of the adrenal glands. Am J Obstet Gynecol 1953;66:970-87.

4. Kita M, Sakalidou M, Saratzis A, et al. Cushing's syndrome in pregnancy: report of a case and review of the literature. Hormones (Athens) 2007;6:242-6.

5. Wallace C, Toth EL, Lewanczuk RZ, et al. Pregnancyinduced Cushing's syndrome in multiple pregnancies. J Clin Endocrinol Metab 1996;81:15-21.

6. Buescher MA, McClamrock HD, Adashi EY. Cushing syndrome in pregnancy. Obstet Gynecol 1992;79:130-7.

7. Pickard J, Jochen AL, Sadur CN, et al. Cushing's syndrome in pregnancy. Obstet Gynecol Surv 1990;45:87-93.

8. Abdelmannan D, Aron DC. Adrenal disorders in pregnancy. Endocrinol Metab Clin North Am 2011;40:779-94.

9. Aron DC, Schnall AM, Sheeler LR. Cushing's syndrome and pregnancy. Am J Obstet Gynecol 1990;162:244-52.

10. Brue T, Amodru V, Castinetti F. Management of endocrine disease: management of Cushing's syndrome during pregnancy: solved and unsolved questions. Eur J Endocrinol 2018;178:R259-66.

11. Chui MH, Ozbey NC, Ezzat S, et al. Case report: Adrenal LH/hCG receptor overexpression and gene amplification causing pregnancy-induced Cushing's syndrome. Endocr Pathol 2009;20:256-61.

12. Wy LA, Carlson HE, Kane P, et al. Pregnancy-associated Cushing's syndrome secondary to a luteinizing hormone/ human chorionic gonadotropin receptor-positive adrenal carcinoma. Gynecol Endocrinol 2002;16:413-7.

13. Lacroix A, Ndiaye N, Tremblay J, et al. Ectopic and abnormal hormone receptors in adrenal Cushing's syndrome. Endocr Rev 2001;22:75-110.

14. Odagiri E, Ishiwatari N, Abe $\mathrm{Y}$, et al. Hypercortisolism and the resistance to dexamethasone suppression during gestation. Endocrinol Jpn 1988;35:685-90.

15. Lacroix A, Feelders RA, Stratakis CA, et al. Cushing's syndrome. Lancet 2015;386:913-27.

16. Casson IF, Davis JC, Jeffreys RV, et al. Successful 
management of Cushing's disease during pregnancy by transsphenoidal adenectomy. Clin Endocrinol (Oxf) 1987;27:423-8.

17. Ross RJ, Chew SL, Perry L, et al. Diagnosis and selective cure of Cushing's disease during pregnancy by transsphenoidal surgery. Eur J Endocrinol 1995;132:722-6.

18. Lindholm J, Schultz-Möller N. Plasma and urinary cortisol in pregnancy and during estrogen-gestagen treatment. Scand J Clin Lab Invest 1973;31:119-22.

19. Pricolo VE, Monchik JM, Prinz RA, et al. Management of Cushing's syndrome secondary to adrenal adenoma during pregnancy. Surgery 1990;108:1072-7; discussion 1077-8.

20. Pinette MG, Pan YQ, Oppenheim D, et al. Bilateral inferior petrosal sinus corticotropin sampling with corticotropin-releasing hormone stimulation in a pregnant patient with Cushing's syndrome. Am J Obstet Gynecol 1994;171:563-4.

21. Cabezón C, Bruno OD, Cohen M, et al. Twin pregnancy in a patient with Cushing's disease. Fertil Steril 1999;72:371-2.

22. Lo KW, Lau TK. Cushing's syndrome in pregnancy secondary to adrenal adenoma. A case report and literature review. Gynecol Obstet Invest 1998;45:209-12.

23. Martínez García R, Martínez Pérez A, Domingo del Pozo C, et al. Cushing's syndrome in pregnancy. Laparoscopic adrenalectomy during pregnancy: the mainstay treatment. J Endocrinol Invest 2016;39:273-6.

24. Owens PC, Smith R, Brinsmead MW, et al. Postnatal disappearance of the pregnancy-associated reduced sensitivity of plasma cortisol to feedback inhibition. Life Sci 1987;41:1745-50.

25. Sammour RN, Saiegh L, Matter I, et al. Adrenalectomy for adrenocortical adenoma causing Cushing's syndrome in pregnancy: a case report and review of literature. Eur J Obstet Gynecol Reprod Biol 2012;165:1-7.

26. Jacobs JK, Goldstein RE, Geer RJ. Laparoscopic adrenalectomy. A new standard of care. Ann Surg 1997;225:495-501; discussion 501-2.

27. Upadhyay A, Stanten S, Kazantsev G, et al. Laparoscopic management of a nonobstetric emergency in the third trimester of pregnancy. Surg Endosc 2007;21:1344-8.

28. Mellor A, Harvey RD, Pobereskin LH, et al. Cushing's disease treated by transsphenoidal selective adenomectomy in mid-pregnancy. Br J Anaesth 1998;80:850-2.

29. Blanco C, Maqueda E, Rubio JA, et al Cushing's syndrome during pregnancy secondary to adrenal adenoma: metyrapone treatment and laparoscopic adrenalectomy. J Endocrinol Invest 2006;29:164-7.

30. Close CF, Mann MC, Watts JF, et al. ACTH-independent Cushing's syndrome in pregnancy with spontaneous resolution after delivery: control of the hypercortisolism with metyrapone. Clin Endocrinol (Oxf) 1993;39:375-9.

31. Gormley MJ, Hadden DR, Kennedy TL, et al. Cushing's syndrome in pregnancy--treatment with metyrapone. Clin Endocrinol (Oxf) 1982;16:283-93.

32. Berwaerts J, Verhelst J, Mahler C, et al. Cushing's syndrome in pregnancy treated by ketoconazole: case report and review of the literature. Gynecol Endocrinol 1999;13:175-82.

33. Amado JA, Pesquera C, Gonzalez EM, et al. Successful treatment with ketoconazole of Cushing's syndrome in pregnancy. Postgrad Med J 1990;66:221-3.

34. Prebtani AP, Donat D, Ezzat S. Worrisome striae in pregnancy. Lancet 2000;355:1692.

35. Nieman LK, Biller BM, Findling JW, et al. Treatment of Cushing's syndrome: an endocrine society clinical practice guideline. J Clin Endocrinol Metab 2015;100:2807-31.

36. Peacey SR, Guo CY, Robinson AM, et al. Glucocorticoid replacement therapy: are patients over treated and does it matter? Clin Endocrinol (Oxf) 1997;46:255-61.

37. Howlett TA. An assessment of optimal hydrocortisone replacement therapy. Clin Endocrinol (Oxf) 1997;46:263-8.

38. Bornstein SR, Allolio B, Arlt W, et al. Diagnosis and treatment of primary adrenal insufficiency: an endocrine society clinical practice guideline. J Clin Endocrinol Metab 2016;101:364-89.

39. Esteban NV, Loughlin T, Yergey AL, et al. Daily cortisol production rate in man determined by stable isotope dilution/mass spectrometry. J Clin Endocrinol Metab 1991;72:39-45.

40. Bancos I, Hahner S, Tomlinson J, et al. Diagnosis and management of adrenal insufficiency. Lancet Diabetes Endocrinol 2015;3:216-26.

Cite this article as: Lin W, Huang HB, Wen JP, Wang NY, Wang SY, Wang C, Chen G. Approach to Cushing's syndrome in pregnancy: two cases of Cushing's syndrome in pregnancy and a review of the literature. Ann Transl Med 2019;7(18):490. doi: 10.21037/atm.2019.07.94 